\title{
Application of a Phase Field Model to Multicomponent Al-Cu-Si alloys
}

\author{
Bruna Norat Bezerra ${ }^{a}$, Diego José Sacramento Ferreira ${ }^{a}$, Alexandre Furtado Ferreira ${ }^{b}$, \\ Amauri Garciac, Ivaldo Leão Ferreira ${ }^{a *}$ (1) \\ ${ }^{a}$ Universidade Federal do Pará (UFPA), Faculdade de Engenharia Mecânica, Rua: Augusto Corrêa 1, \\ 66075-110, Belém, PA, Brasil \\ ${ }^{b}$ Universidade Federal Fluminense, Programa de Pós-Graduação em Engenharia Metalúrgica, \\ Av. dos Trabalhadores 420, 27255-125, Volta Redonda, RJ, Brasil \\ 'Universidade de Campinas (UNICAMP), Departamento de Engenharia e Manufatura de Materiais, \\ 13083-860, Campinas, SP, Brasil
}

Received: May 7, 2020; Accepted: June 18, 2020

\begin{abstract}
The solidification of metals and alloys and the resulting microstructures, which as a function of thermal and solutal parameters can evolve as planar, cellular and dendritic, are important from a practical point of view, since they strongly influence the properties and quality of the final product. In many practical situations it is impracticable to develop analytical solutions permitting reliable predictions of microstructural growth during unsteady-state solidification conditions. The Phase Field method has become very popular and effective in modeling complex solid/liquid interfaces due to its ability to simulate the interface kinetics and the formation and evolution of different morphologies along the solidification process. In this work, a numerical analysis of the microstructural evolution during the transient solidification of dilute alloys of the Al-Cu-Si system is developed, which uses a phasefield approach for the simulation of ternary alloys. The phase-field, energy and solute concentration equations were numerically solved for the correspondent ternary system, varying the mesh parameters, temperature and alloy composition. The analysis performed were confronted with existing theoretical models and the results obtained are in agreement with the solidification theory.
\end{abstract}

Keywords: Phase field method; Aluminum alloys; Multicomponent alloys; Microstructural development.

\section{Introduction}

Understanding the solidification process and the main microstructures arising from it, are extremely important from a practical standpoint, given that they exert a strong influence on the resulting properties of the products. Although significant advances have been achieved in understanding microstructural formation in past decades, our knowledge concerning microstructural growth is mainly based on experiments and idealized theoretical models. Appreciable attention has been paid, in the open literature, to the simulation of microstructural growth and related phenomena. Several different numerical approaches have been, and continue to be, proposed to that end.

The phase-field models are known to be an interesting methodology for simulating the pattern evolution of the interface between mother and new phases under non-equilibrium state due to all its governing equations are written in a unified manner in the whole space of the computational domain. Furthermore, direct tracking of the interface position is not needed during calculations of the solidification evolution. It should be noted that the morphology of the solid/liquid interface, that is, the solidification front, as calculated by phase-field model, reproduces the known patterns of the

"e-mail: ileao@ufpa.br microstructures resulting from the solidification process. The state of the computational domain is represented by a distribution of the single variable known as "order parameter" or "phase-field variable". In the present study, the solid state will be represented by a phase field variable equal to +1 while in the liquid region its value is 0 (zero). The region in which it changes progressively from 0 to +1 is defined as the liquid/solid interface, the region where solidification effectively takes place.

The phase-field models were developed mainly for simulating solidification of pure materials, being subsequently extended to the solidification of binary, ternary and quaternary alloys. The first models focused on pure materials, such was the case of Kobayashi ${ }^{1}$, Kim et al. ${ }^{2}$ and Furtado et al. ${ }^{3}$. Binary alloys were then investigated by Lee et al. ${ }^{4}$ and Kim et al. ${ }^{5}$. Next, ternary alloys were explored by Ode et al. ${ }^{6}$ and Ferreira et al. ${ }^{7}$. Quaternary Fe-C-Mn-P alloys were examined by Salvino et al. ${ }^{8}$.

Solidification is the main phenomenon taking place during casting. This, in turn, has long been known as an inexpensive means for producing metallic parts. Nowadays, a sizable portion of the concepts and methods developed over the years in support of the research on solidification processes can be successfully and economically translated to industrial 
scale. Copper, silicon and magnesium are the main alloying elements added to aluminum-based casting alloys. It is widely recognized that moderate addition of copper to aluminum, especially when added together with silicon, significantly improves the resulting mechanical properties as far as it decreases surface tension and viscosity as demonstrated by Ferreira et al. ${ }^{9}$. The automotive industry is the main area where aluminum-based casting alloys are applied. This is due to their good casting characteristics, weldability and corrosion resistance, according to Sales et al. ${ }^{10}$.

The mechanical properties of as-cast alloys are strongly influenced by the microstructures resulting from the solidification process. In order to obtain aluminum billets that will give the best mechanical properties, it is very important to distinguish and control the as-cast structures. The microstructure resulting from solidification directly influences the material properties, not only the morphology of the structure itself, such as dendrites and cells, but also inclusions, porosities and segregation, as discussed by Paradela et al. ${ }^{11}$.

Concerning the relation between dendrite microstructural development and mechanical properties. Kim et al. ${ }^{12}$, proposed an analysis of the relationship between microstructure and mechanical properties of $\mathrm{Al}-\mathrm{Cu}-\mathrm{Si}$ ultrafine eutectic composites and its dependence on the length scale, volume fraction, and crystallinity. Kim et al. ${ }^{13}$ studied the microstructure and mechanical properties of hierarchical multi-phase composites based on Al-Ni-type intermetallic compounds in the Al-Ni-Cu-Si alloy system. Kim et al. ${ }^{13}$ investigated the cooperative deformation behavior between the shear band and boundary sliding of an Al-based nanostructuredendrite composite and noticed that high yield strength and intermediate plasticity are both due to the evolution of dislocations in the microscale dendrites associated with the cooperative deformation of the shear band, and interfacial sliding throughout the volume ${ }^{14}$.

Segregation is an important phenomenon that can induce non-uniformity in mechanical properties and affect corrosion resistance. Microsegregation, which refers to localized differences in composition between cells or dendrite arms, cannot be avoided during solidification since it is the result of the solubility difference between liquid and solid regions. An understanding of the way microsegregation occurs in the solidification process can be of great importance for mechanical properties of as-cast materials and in designing post-casting process such as heat treatments. The design of the homogenization heat treatment of as-cast materials is dependent on the microsegregation level ${ }^{8}$.

It is in this general framework that the present work is developed, i.e. a numerical investigation by a phase-field model with focus on solidification of hypoeutectic $\mathrm{Al}-\mathrm{Cu}-\mathrm{Si}$ alloys. In order to analyze the microstructural evolution during the transient solidification, simulations were carried out for the set of dilute alloys compositions. The governing equations (phase-field itself, energy and concentrations) were numerically solved for ternary alloys considering variable mesh parameters, temperature and composition. The analysis performed is confronted with fundamental theoretical models (Lever Rule and Scheil's equation).

\section{Phase Field Formulation}

Kim at al. have considered the idea to their thin interface limit model in a thermodynamically consistent way ${ }^{2}$. According to Ode et al. ${ }^{6}$ the model is equivalent to the WBM model $^{15}$ but the free energy density at the interface has a different definition. The extra potential in the WBM model disappears in the model because of the free energy function corresponding to the common tangent itself, thus permitting to make calculations with a larger mesh size. This makes possible to apply a vanishing kinetic coefficient by adjusting the parameters with any mesh size. Ode et al. ${ }^{6}$ extended the Kim et al. ${ }^{2}$ model to ternary alloys, but considering an isothermal solution applied to Fe-C-P alloys. Here, we extend their model for non-isothermal quaternary alloys and applied it to the Al-Cu-Si alloy system.

As described by Ode et al. ${ }^{6}$ for ternary alloys, the governing equations for a quaternary non-isothermal phase field model for dilute alloys consists in the following set of chemical potential equations,

$$
\begin{gathered}
\mu_{C u, S}^{0}+\frac{R T}{\forall} \ln \left(\gamma_{C u}^{S} C_{C u, S}^{E q}\right)=\mu_{C u, L}^{0}+\frac{R T}{\forall} \ln \left(\gamma_{C u}^{L} C_{C u, L}^{E q}\right) \\
\mu_{S i, S}^{0}+\frac{R T}{\forall} \ln \left(\gamma_{S i}^{S} C_{S i, S}^{E q}\right)=\mu_{S i, L}^{0}+\frac{R T}{\forall} \ln \left(\gamma_{S i}^{L} C_{S i, L}^{E q}\right) \\
\mu_{M g, S}^{0}+\frac{R T}{\forall} \ln \left(\gamma_{M g}^{S} C_{M g, S}^{E q}\right)=\mu_{M g, L}^{0}+\frac{R T}{\forall} \ln \left(\gamma_{M g}^{L} C_{M g, L}^{E q}\right) \\
\mu_{A l, S}^{0}+\frac{R T}{\forall} \ln \left[1-\left(C_{C u, S}^{E q}+C_{S i, S}^{E q}+C_{M g, S}^{E q}\right)\right]= \\
\mu_{A l, L}^{0}+\frac{R T}{\forall} \ln \left[1-\left(C_{C u, L}^{E q}+C_{S i, L}^{E q}+C_{M g, L}^{E q}\right)\right]
\end{gathered}
$$

where $\mu_{i, S}^{0}$ is the standard state chemical potential of species $i$. Subscripts $L$ and $S$ represent liquid and solid phases, respectively. The superscript $E q$ means equilibrium state. $\gamma_{i}$ is the activity coefficient of the species $i . R$ is the universal gas constant. $T$ is the absolute temperature and $\forall$ is the solvent molar volume.

The free energy density is the linear combination of the free energy for liquid and solid bulk phases and the double-well potential ${ }^{6}$, expressed as,

$$
\begin{aligned}
& f=h(\phi) f_{S}\left(C_{C u, S}, C_{S i, S}, C_{M g, S}\right)+ \\
& {[1-h(\phi)] f_{l}\left(C_{C u, L}, C_{S i, L}, C_{M g, L}\right)+W g(\phi)}
\end{aligned}
$$

i.e.,

$$
\begin{aligned}
& f=h(\phi)\left[\begin{array}{l}
C_{C u, S} \mu_{C u, S}+C_{S i, S} \mu_{S i, S}+C_{M g, S} \mu_{M g, S}+ \\
{\left[\begin{array}{l}
\left.1-\left(C_{C u, S}+C_{S i, S}+C_{M g, S}\right)\right] \mu_{A l, S}
\end{array}\right]+} \\
{[1-h(\phi)]\left[\begin{array}{l}
C_{C u, L} \mu_{C u, L}+C_{S i, S} \mu_{S i, L}+C_{M g, S} \mu_{M g, L}+ \\
{\left[1-\left(C_{C u, L}+C_{S i, L}+C_{M g, L}\right)\right] \mu_{A l, L}}
\end{array}\right]+W g(\phi)}
\end{array}\right.
\end{aligned}
$$

where, $W$ is the height of the double-well potential. $h(\phi)$ and $g(\phi)$ are defined as,

$$
h(\phi)=\phi^{3}\left(6 \phi^{2}-15 \phi+10\right)
$$

and

$$
g(\phi)=\phi^{2}(1-\phi)^{2}
$$


The phase field equation is taken as,

$$
\frac{1}{M} \frac{\partial \phi}{\partial t}=\varepsilon^{2} \nabla^{2} \phi-f_{\phi}
$$

where $\phi$ is the phase-field denoting liquid $(\phi=0)$ and solid $(\phi=1)$ phases, $\varepsilon$ is the gradient energy coefficient and $M$ is the phase-field mobility.

The concentration field equation for quaternary dilute alloys, in the same way as assumed by Ode et al. ${ }^{6}$, is derived as

$$
\frac{\partial C_{i}}{\partial t}=\nabla \cdot\left(\frac{D_{i}(\phi)}{f_{C_{i} C_{i}}} \nabla f_{C_{i}}\right)
$$

where the subscripts under $f$ means the first and second partial derivatives with respect to the concentration of species .

In Equation 10 the diffusion coefficient must obey the following conditions:

$$
D_{i}(\phi)=D_{i, S}(\phi) \text { if } \phi>0.9
$$

or,

$$
D_{i}(\phi)=D_{i, L}(\phi) \text { if } \phi \leq 0.9
$$

where $D_{i, S}$ and $D_{i, L}$ are the solid and liquid phase diffusion coefficients $\left[\mathrm{m}^{2} / \mathrm{s}\right]$. For all species in the present model, the chemical potential of solid and liquid phases are assumed to be the same. The concentration is assumed in terms of solid and liquid concentrations as,

$$
C_{i}=h(\phi) C_{i, S}+[1-h(\phi)] C_{i, L}
$$

For dilute quaternary alloys, the set of governing equations for the phase-field, solute diffusion and energy transport are the following:

$$
\frac{1}{M} \frac{\partial \phi}{\partial t}=\varepsilon^{2} \nabla^{2} \phi+\frac{R T}{\forall} \ln \left\{\left[\begin{array}{l}
{\left[1-\left(\begin{array}{l}
C_{C,, S}^{E q}+ \\
C_{S i, S}^{E q}+C_{M g, S}^{E q}
\end{array}\right)\right]\left[1-\left(\begin{array}{l}
C_{C u, L}+ \\
C_{S i, L}+C_{M g, L}
\end{array}\right)\right]} \\
{\left[1-\left(\begin{array}{l}
C_{C, L}^{E q}+ \\
C_{S i, L}^{E q}+C_{M g, L}^{E q}
\end{array}\right)\right]\left[1-\left(\begin{array}{l}
C_{C u, S}+ \\
C_{S i, S}+C_{M g, S}
\end{array}\right)\right]}
\end{array}\right\} h^{\prime}(\phi)-W g^{\prime}(\phi)\right.
$$

where, $h^{\prime}(\phi)$ and $g^{\prime}(\phi)$ are derivatives of Equation 7 and Equation 8 with respect to $\phi$, respectively.

Ode et al. ${ }^{6}$ proposed a solute diffusion equation for ternary alloys, here extended for quaternary alloys, as follows,

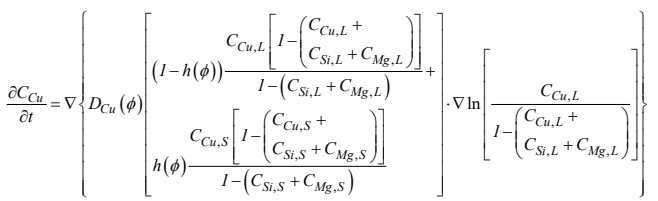

$$
\frac{\partial C_{S i}}{\partial t}=\nabla\left\{D_{S i}(\phi)\left[\begin{array}{c}
(1-h(\phi)) \frac{C_{S i, L}\left[1-\left(\begin{array}{l}
C_{C u, L}+ \\
C_{S i, L}+C_{M g, L}
\end{array}\right)\right]}{1-\left(C_{C u, L}+C_{M g, L}\right)} \\
h(\phi) \frac{C_{S i, S}\left[1-\left(\begin{array}{l}
C_{C u, S}+ \\
\left.C_{S i, S}+C_{M g, S}\right)
\end{array}\right]\right.}{1-\left(C_{C u, S}+C_{M g, S}\right)}
\end{array}\right] \cdot \nabla \ln \left[\frac{C_{S i, L}}{1-\left(\begin{array}{l}
C_{C u, L}+ \\
C_{S i, L}+C_{M g, L}
\end{array}\right)}\right]\right\}
$$

$$
\frac{\partial C_{M g}}{\partial t}=\nabla\left\{D_{M g}(\phi)\left[\begin{array}{c}
(1-h(\phi)) \frac{C_{M g, L}\left[1-\left(\begin{array}{l}
C_{C u, L}+ \\
C_{S i, L}+C_{M g, L}
\end{array}\right)\right]}{1-\left(C_{C u, L}+C_{S i, L}\right)} \\
C_{M g, S}\left[1-\left(\begin{array}{l}
C_{C u, S}+ \\
C_{S i, S}+C_{M g, S}
\end{array}\right)\right] \\
h(\phi) \frac{1-\left(C_{C u, S}+C_{S i, S}\right)}{l}
\end{array}\right] \cdot \nabla \ln \left[\frac{C_{M g, L}}{1-\left(\begin{array}{l}
C_{C u, L}+ \\
C_{S i, L}+C_{M g, L}
\end{array}\right)}\right]\right\}
$$

According to Zhao et al. ${ }^{16}$, the energy equation can be written as,

$$
c_{P} \frac{\partial T}{\partial t}=\nabla k \nabla T+\Delta H h_{P}^{\prime}(\phi) \frac{\partial \phi}{\partial t}
$$

where $T$ is the absolute temperature, $k$ is the thermal conductivity, $\Delta H$ is the latent heat of fusion, and, $c_{P}$ is the specific heat defined by the mixture rule as,

$$
c_{P}=c_{P S}+\left[1-h_{P}(\phi)\right] c_{P S}
$$

According to Zhao et al. ${ }^{16}$, the phase field Equations 5-8 does not obey any energy dissipation law. Thus, in order to properly solve a coupled phase field-energy equation system, a consistent temperature discretization scheme for the energy equation must consider a first and second order time discretization scheme, as the following. In this study the energy equation is assumed as a first order time discretization scheme, that is,

$$
\frac{T^{n+1}-T^{n}}{\delta t}=\frac{k}{c_{P}} \Delta T^{n+1}+\frac{\Delta H}{c_{P}} h_{P}^{\prime}(\phi) \frac{\phi^{n+1}-\phi^{n}}{\delta t}
$$

\section{Microsegregation Relations}

The Lever Rule equation can be written in terms of solute concentration and solid fraction as,

$$
C_{s}=\frac{k C_{0}}{\left[1-(1-k) f_{s}\right]}
$$

where, $k$ is the equilibrium partition coefficient, $C_{0}$ is the initial concentration, $C_{s}$ concentration of the solid phase and $f_{s}$ is the solid fraction.

Regarding the situation where no solute diffusion in the solid phase occurs, infinite diffusion in the liquid phase takes place and equilibrium exists at the solid-liquid interface. The solidus and liquidus isotherms are assumed as straight lines, and the solid concentration can be expressed as,

$$
C_{s}=k C_{0}\left(1-f_{s}\right)^{(k-1)}
$$

Regarding partial mixture of solute in the liquid phase ${ }^{17}$, taking into consideration that the solute mixture occurs only by diffusion for a diffusion length scale $\delta$, and for the remaining volume of liquid the convection streams may be enough to keep a uniform concentration $C_{L}^{*}$, the expression for the effective partition coefficient $\left(\mathrm{k}_{\mathrm{eff}}\right)$, which takes into account the diffusion coefficient of the liquid, the tip growth rate and the diffusion length scale is derived as

$$
k_{\text {eff }}=\frac{k}{k+(1-k) \exp \left(\frac{-v \delta}{D}\right)}
$$

where, $v$ is tip growth rate, $\delta$ is the diffusion length scale in the liquid phase and $D$ is the diffusion coefficient of the liquid phase.

\section{Results and Discussion}

For the results presented in this section, an isothermal solidification regarding $1,5^{\circ} \mathrm{C}$ of undercooling were assumed, as well as a computational domain of $40 \times 120 \mu \mathrm{m}$. 
The physical properties and the phase field parameters used for the simulations carried out for dilute $\mathrm{Al}-\mathrm{Cu}-\mathrm{Si}$ alloys were obtained from Liu et al. ${ }^{18}$ and Ferreira et al. ${ }^{7}$ and presented in Table 1 and Table 2, respectively.

The thermophysical properties for the alloys are provided in Table 3. As can be seen, the values of the thermophysical properties of the alloys are quite similar because of the range of solute compositions examined and were calculated according to the procedures described in previous studies $9,19,20$.
In Figure $1 \mathrm{a}$ phase field non-isothermal simulation is performed for a ternary $\mathrm{Al}-4 \mathrm{wt} \% \mathrm{Cu}-0,1 \mathrm{wt} \% \mathrm{Si}$ considering $1,5^{\circ} \mathrm{C}$ of undercooling and a total simulation time of $\mathrm{t}=0,008506816 \mathrm{~s}$, where: (A) the phase field variable, (B) temperature field, (C) concentration of copper and (D) concentration of silicon. The results observed for phase field, temperature and for solute concentration of copper and silicon are physically consistent with a cellular growth.

Figure. 2 represents the normalized concentrations as a function of the solid fraction for the following aluminum-based

Table 1 - Physical properties of dilute Al-Cu-Si alloys

\begin{tabular}{|c|c|c|c|c|}
\hline \multirow{2}{*}{ Thermophysical Properties, symbol } & \multirow{2}{*}{ Units } & \multicolumn{3}{|c|}{ Value } \\
\hline & & $\mathrm{Al}$ & $\mathrm{Cu}$ & $\mathrm{Si}$ \\
\hline Partition coefficient, $k_{i}$ & & & 0.14 & 0.114 \\
\hline Slope of liquidus isotherm, $m_{i}$ & {$\left[K . \mathrm{mol}^{-1}\right]$} & & 724.63 & 678.81 \\
\hline Diffusion coefficient in the solid phase, $D_{S, i}$ & {$\left[m \cdot s^{-2}\right]$} & & $8.43 \times 10^{-13}$ & $2.91 \times 10^{-12}$ \\
\hline Diffusion coefficient in the liquid phase, $D_{S, i}$ & {$\left[m \cdot s^{-2}\right]$} & & $4.33 \times 10^{-09}$ & $2.46 \times 10^{-09}$ \\
\hline Molar volume of the solvent, $\forall$ & {$\left[m^{3} \cdot m o l^{-1}\right]$} & $1.095 \times 10^{-5}$ & & \\
\hline Solvent melting temperature, $T_{m}$ & {$[K]$} & 933.15 & & \\
\hline Interface energy, $\sigma$ & {$\left[J . m o l{ }^{-2}\right]$} & 0.093 & & \\
\hline
\end{tabular}

Table 2 - Phase field computational parameters.

\begin{tabular}{ccc}
\hline Parameter, symbol & Units & Value \\
\hline Magnitude of anisotropy, $\delta_{e}$ & {$\left[J . m^{-1}\right]^{1 / 2}$} & 0.03 \\
\hline Phase field gradient energy, $\varepsilon_{0}$ & {$\left[J . m^{-3}\right]$} & $1.055 \times 10^{-3}$ \\
\hline Height of double-well potential, $W$ & {$[s]$} & $673.2 \times 10^{3}$ \\
\hline Time step, $d t$ & {$[m]$} & $1.0 \times 10^{-8}$ \\
\hline Mesh size, $\Delta x=\Delta y$ & & $1.0 \times 10^{-8}$ \\
\hline Noise amplitude, $a$ & & 0.03 \\
\hline
\end{tabular}

Table 3 - Thermophysical properties of the examined alloys.

\begin{tabular}{|c|c|c|c|c|c|}
\hline \multirow{2}{*}{ Property, symbol } & \multirow{2}{*}{ Units } & \multicolumn{4}{|c|}{ Values } \\
\hline & & $\mathrm{Al}-0.5 \mathrm{Cu}-0.5 \mathrm{Si}$ & $\mathrm{Al}-2.0 \mathrm{Cu}-0.1 \mathrm{Si}$ & $\mathrm{Al}-2.0-\mathrm{Cu}-1.0 \mathrm{Si}$ & $\mathrm{Al}-4.0 \mathrm{Cu}-0.1 \mathrm{Si}$ \\
\hline Density in the solid phase, $\rho_{S}$ & {$\left[k g \cdot m^{-3}\right]$} & 2646.76 & 2676.40 & 2673.07 & 2711.51 \\
\hline Density in the liquid phase, $\rho_{L}$ & {$\left[\mathrm{~kg} \cdot \mathrm{m}^{-3}\right]$} & 2404.12 & 2424.12 & 2429.15 & 2460.0 \\
\hline Specific heat in the solid phase, $C_{P}$ & {$\left[J . \mathrm{kg}^{-1} \mathrm{~K}^{-1}\right.$} & 1076.0 & 1069.0 & 1066.0 & 1056.0 \\
\hline Specific heat in the solid phase, $C_{L}$ & {$\left[J . \mathrm{kg}^{-1} \mathrm{~K}^{-1}\right.$} & 1169.0 & 1156.0 & 1151.0 & 1136.0 \\
\hline Thermal conductivity in the solid, $k_{S}$ & {$\left[W \cdot m^{-1} K^{-1}\right]$} & 192.5 & 193.35 & 192.6 & 193.6 \\
\hline Thermal conductivity in the liquid, $k_{L}$ & {$\left[W \cdot m^{-1} K^{-1}\right]$} & 82.7 & 82.5 & 82.3 & 82.2 \\
\hline Latent heat, $\Delta H$ & {$\left[J . \mathrm{kg}^{-1}\right]$} & 395500 & 366800 & 368500 & 349800 \\
\hline
\end{tabular}




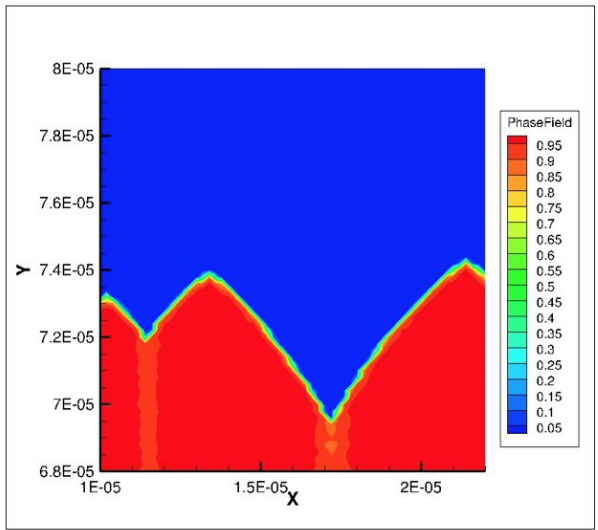

(A)

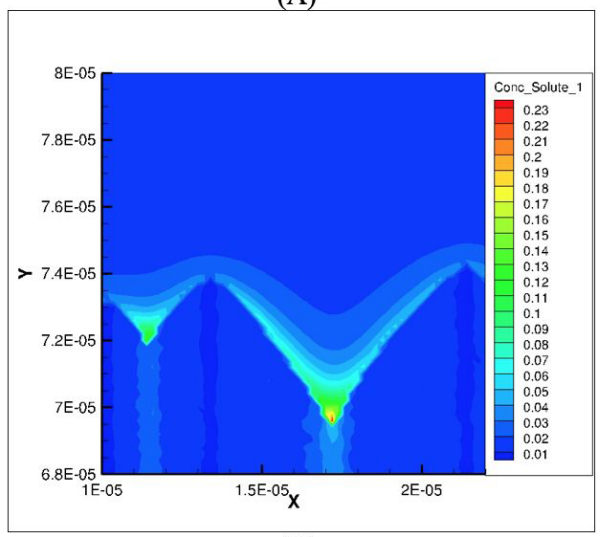

(C)

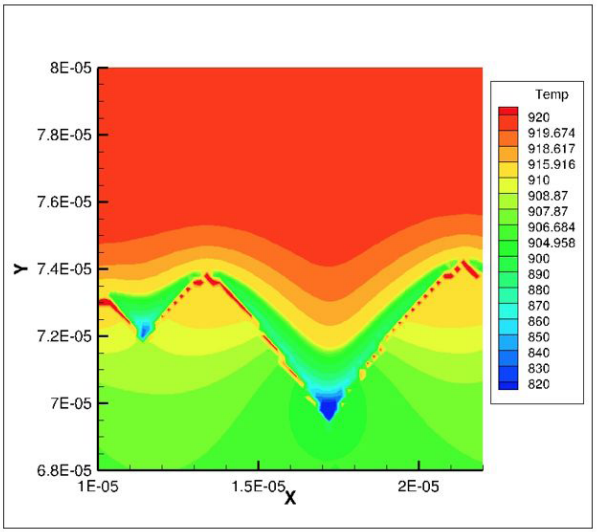

(B)

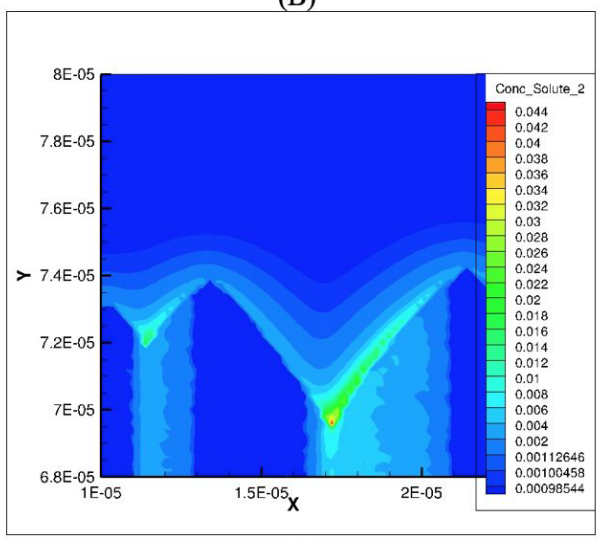

(D)

Figure 1. Phase-field simulation for a ternary Al- $4 \mathrm{wt} \% \mathrm{Cu}-0.1 \mathrm{wt} \% \mathrm{Si}$ alloy for $\mathrm{t}=0.008506816 \mathrm{~s}$ at liquidus temperature (A) magnification of phase field variable of a cellular microstructure, (B) temperature distribution, (C) copper concentration and (D) silicon concentration.

alloys: Al- $0.5 \mathrm{wt} \% \mathrm{Cu}-0.5 \mathrm{wt} \% \mathrm{Si}, \mathrm{Al}-2.0 \mathrm{wt} \% \mathrm{Cu}-0.1 \mathrm{wt} \% \mathrm{Si}$, $\mathrm{Al}-2.0 \mathrm{wt} \% \mathrm{Cu}-1.0 \mathrm{wt} \% \mathrm{Si}$ and $\mathrm{Al}-2.0 \mathrm{wt} \% \mathrm{Cu}-1.0 \mathrm{wt} \% \mathrm{Si}$ under isothermal solidification subjected to $1,5^{\circ} \mathrm{C}$ undercooling for the Lever Rule, Scheil Equation ${ }^{21}$ and phase field model. As can be noticed, the $\mathrm{Cu}$ concentrations have strong trend towards the Lever Rule, nevertheless, the level of back diffusion in the solid is lower than that yielded by the equilibrium phase diagram, i.e., the Lever Rule, characterizing the so-called finite back-diffusion in the solid. This phenomenon is better understood in terms of the back-diffusion parameter in the solid $(\beta)$ whose limit cases are, $\beta=1$ infinite back-diffusion in the solid (Lever Rule), $\beta=0$ no back diffusion in the solid (Scheil Equation) and $0<\beta<1$, finite back-diffusion in the solid $^{22,23}$. The $\mathrm{Cu}$ concentrations predicted by phase-field simulation have a trend to be closer to the Lever Rule, while the $\mathrm{Si}$ concentrations are closer to the Scheil Equation, as observed in Figure 2 (A2) and (B2). In the case of Figure 2 (C2) the phase-field concentration of $\mathrm{Si}$ is found to be in between the Lever Rule and the Scheil Equation.

Figure 3 shows the partition coefficient $\left(k_{e}\right)$ as a function of position for the $\mathrm{Al}-0.5 \mathrm{wt} \% \mathrm{Cu}-0.5 \mathrm{wt} \% \mathrm{Si}, \mathrm{Al}-2 \mathrm{wt} \% \mathrm{Cu}-0.1 \mathrm{wt} \% \mathrm{Si}$, $\mathrm{Al}-2 \mathrm{wt} \% \mathrm{Cu}-1.0 \mathrm{wt} \% \mathrm{Si}$ and $\mathrm{Al}-4 \mathrm{wt} \% \mathrm{Cu}-1.0 \mathrm{wt} \% \mathrm{Si}$ alloys for $\mathrm{Cu}$ and $\mathrm{Si}$, calculated by the phase-field model. The results state that this behavior is in accordance with the theoretical limits, i.e. the equilibrium partition coefficient $\left(k_{0}\right)$ and the effective partition coefficient $\left(k_{e f f}\right)$. At the final instances of the phase-field calculations, an approximation towards the curve of the effective partition coefficient is observed. Indeed, the values provided by the phase-field model have a gradual growth. It means that for all cases, the effective partition coefficient overestimates the solute redistribution predicted by the phase-field model.

Figure 4 presents the diffusion length scale for $\mathrm{Cu}$ and $\mathrm{Si}$ as a function of the solid fraction. As can be observed, there's a predominance of higher diffusion length scale values for $\mathrm{Cu}$ in relation to those of $\mathrm{Si}$, which directly contribute to raise the corresponding effective partition coefficients ${ }^{24,25}$.

Figure 5 shows the tip growth rate as a function of time for all the analyzed alloys. The tip growth rates are around a mean value for each alloy for all times, with lower solute concentrations providing higher tip growth rates, except for the $\mathrm{Al}-2 \mathrm{wt} \% \mathrm{Cu}-1.0 \mathrm{wt} \% \mathrm{Si}$ and $\mathrm{Al}-4 \mathrm{wt} \% \mathrm{Cu}-0.1 \mathrm{wt} \% \mathrm{Si}$ alloys that have similar values. Nevertheless, the initial behavior follows the concentration trend, and after that, both curves are very close to each other until solidification is complete. It is worth noting that the computational domain is very small $\left({ }^{120 \mu m}\right)$, and decrease in the solidification growth rate with time is not expected because of the considerably low thermal resistance.

Figure 6 represents the cellular spacing $(\lambda c)$ as a function of position. It can be noticed that the cellular spacing grows for all alloys, as the solidification proceeds until it stabilizes around certain value at the final stages of solidification. An exception is verified in the case of $\mathrm{Al}-2 \mathrm{wt} \% \mathrm{Cu}-0.1 \mathrm{wt} \% \mathrm{Si}$ 


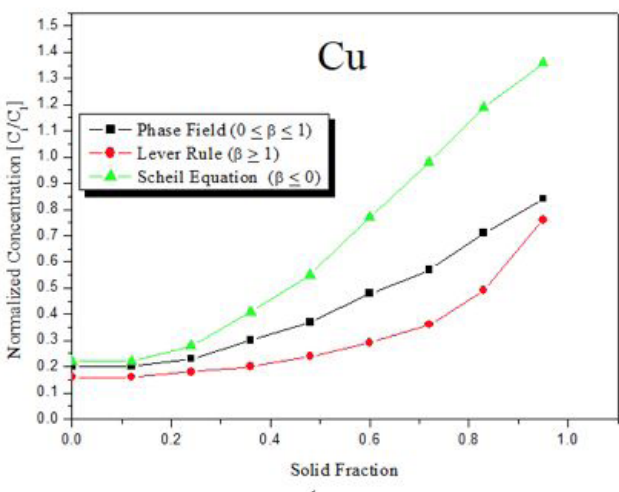

(A1)

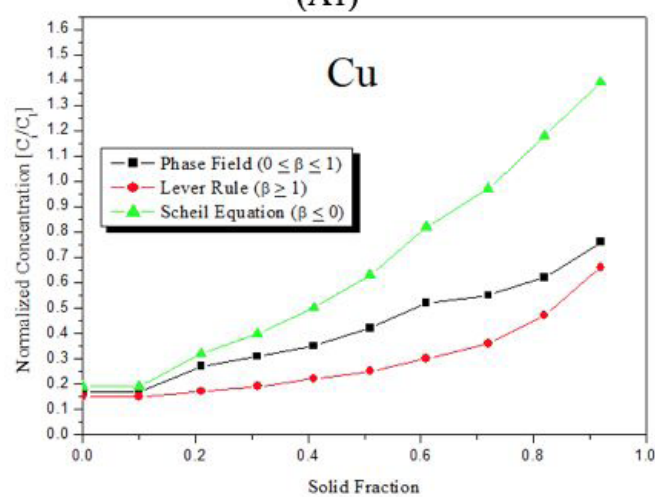

(B1)

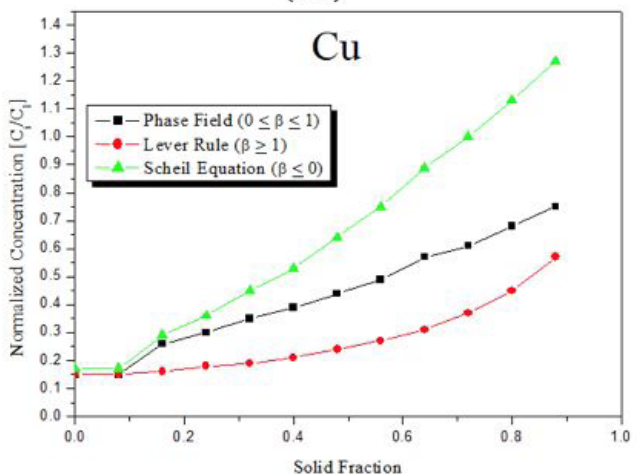

(C1)

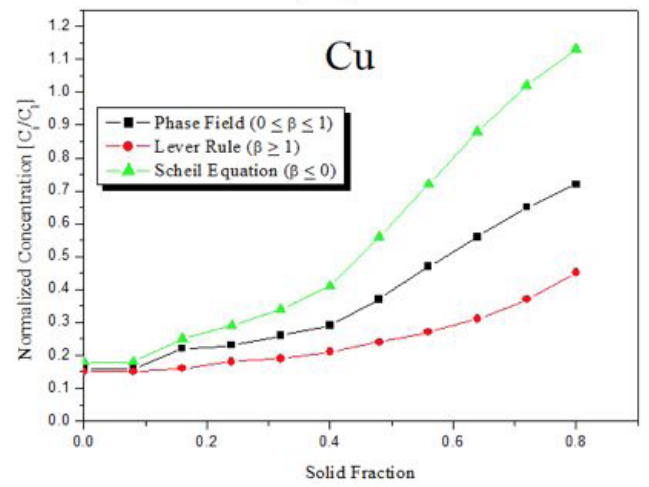

(D1)

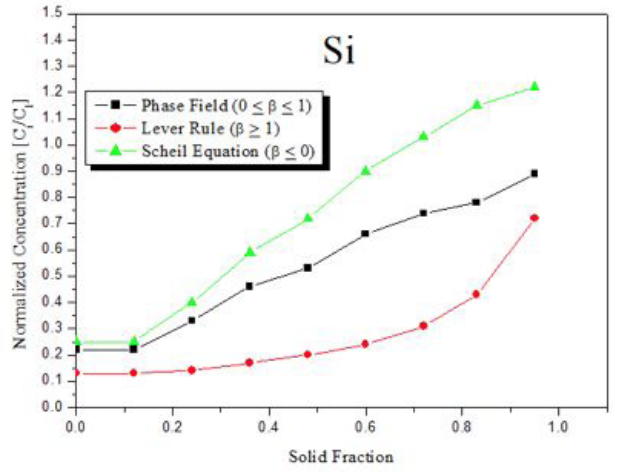

(A2)

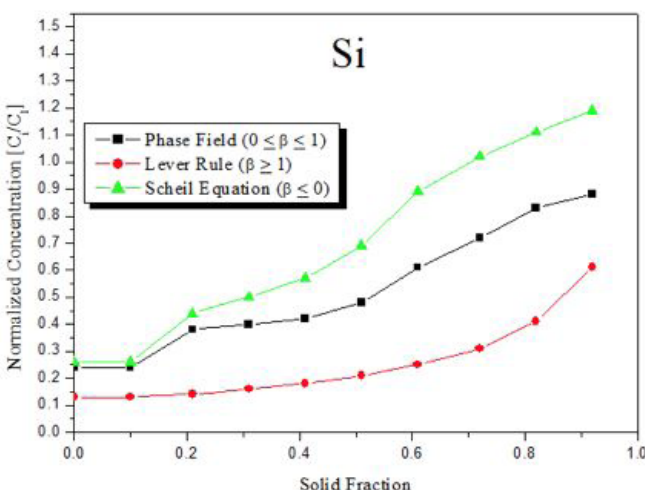

(B2)

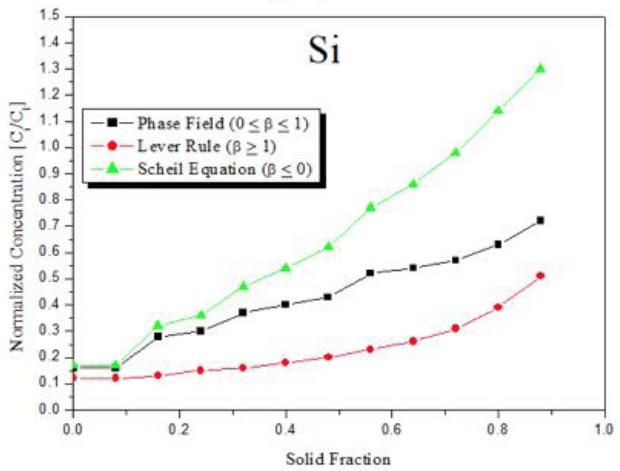

(C2)

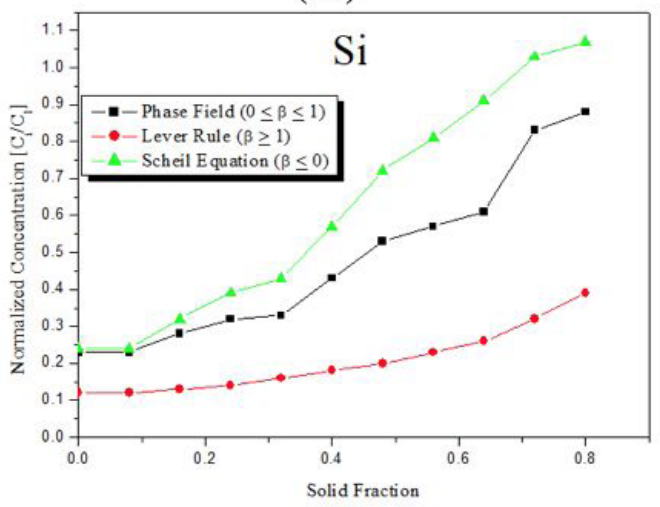

(D2)

Figure 2. Normalized concentration as a function of the solid fraction for: (A) Al- $0.5 \mathrm{wt} \% \mathrm{Cu}-0.5 \mathrm{wt} \% \mathrm{Si}$, (B) $\mathrm{Al}-2.0 \mathrm{wt} \% \mathrm{Cu}-0.1 \mathrm{wt} \% \mathrm{Si}$, (C) $\mathrm{Al}-2.0 \mathrm{wt} \% \mathrm{Cu}-1.0 \mathrm{wt} \% \mathrm{Si}$, and (D) $\mathrm{Al}-4.0 \mathrm{wt} \% \mathrm{Cu}-0.1 \mathrm{wt} \% \mathrm{Si}$ alloys. 


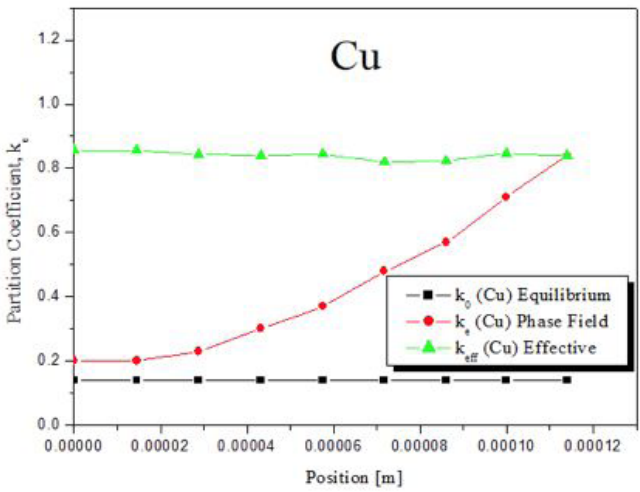

(A1)

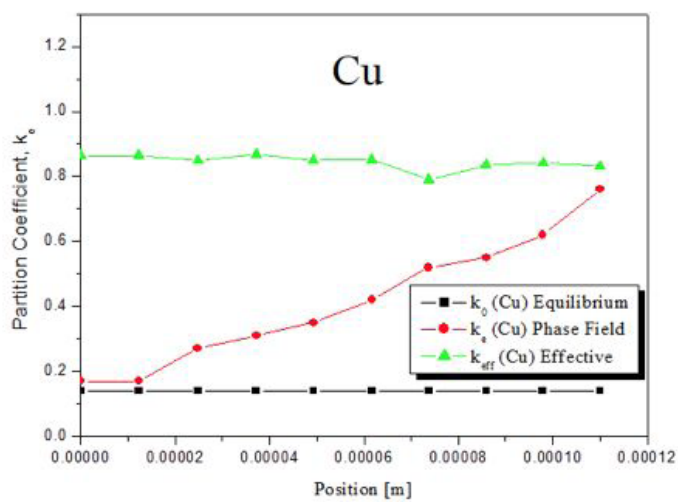

(B1)

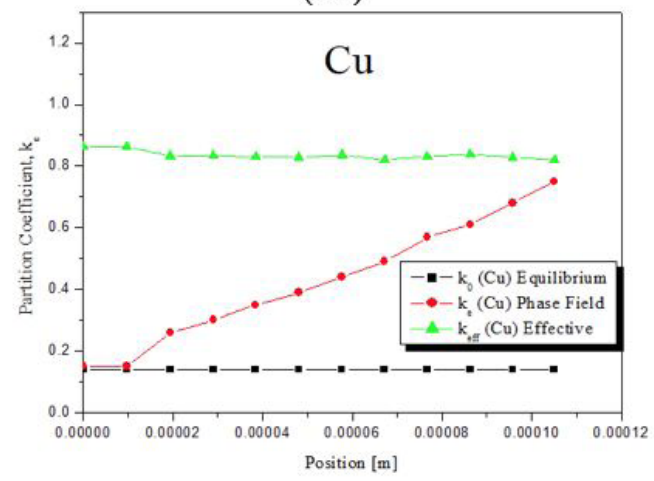

(C1)

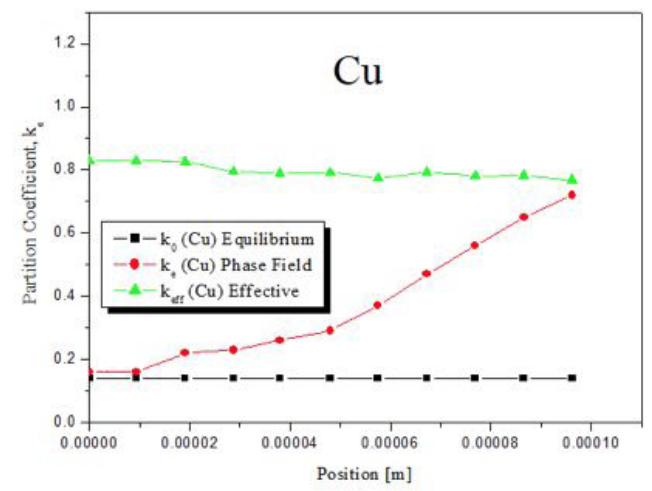

(D1)

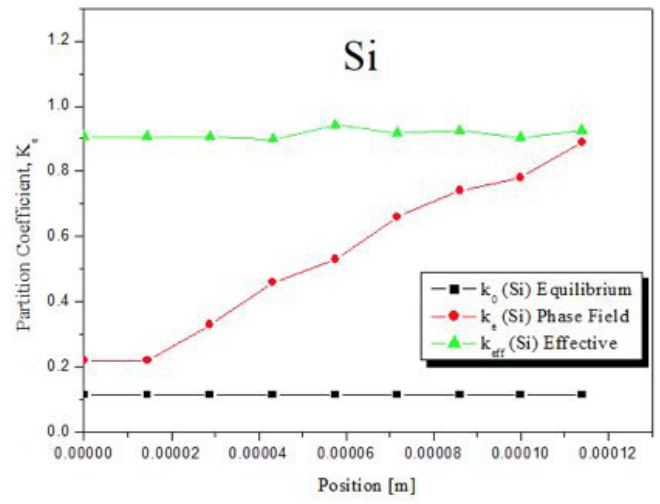

(A2)

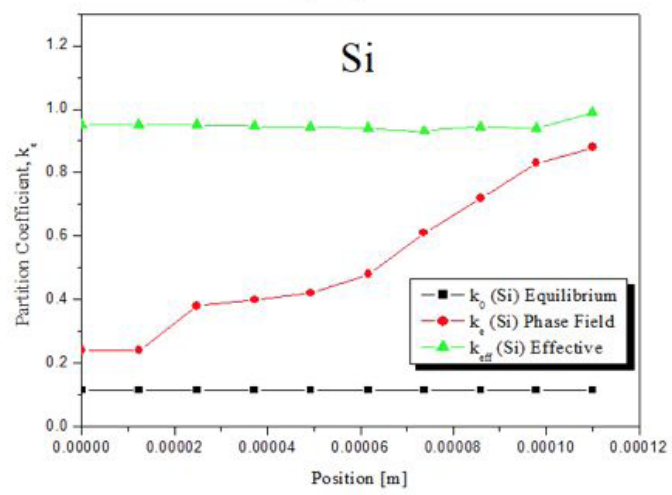

(B2)

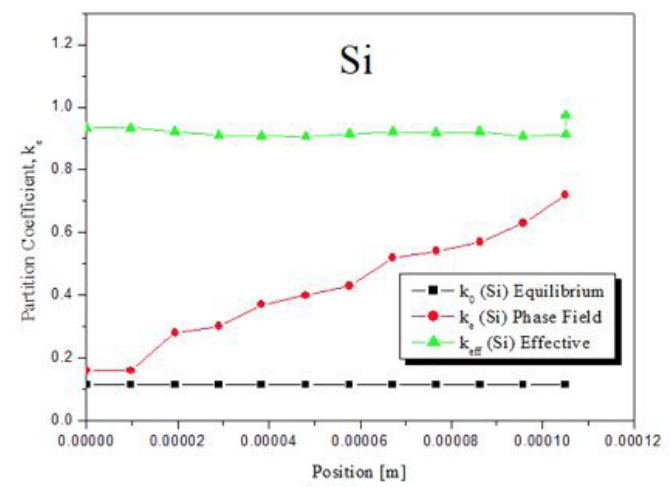

(C2)

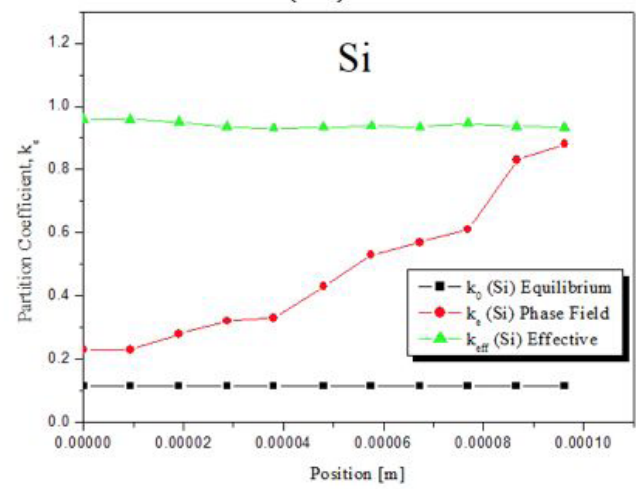

(D2)

Figure 3. Partition coefficient as a function of sample position for: (A) Al- $0.5 w t \% \mathrm{Cu}-0.5 \mathrm{wt} \% \mathrm{Si}$, (B) $\mathrm{Al}-2.0 \mathrm{wt} \% \mathrm{Cu}-0.1 \mathrm{wt} \% \mathrm{Si}$, (C) $\mathrm{Al}-2.0 \mathrm{wt} \% \mathrm{Cu}-1.0 \mathrm{wt} \% \mathrm{Si}$, (D) $\mathrm{Al}-4.0 \mathrm{wt} \% \mathrm{Cu}-0.1 \mathrm{wt} \% \mathrm{Si}$ alloys. 


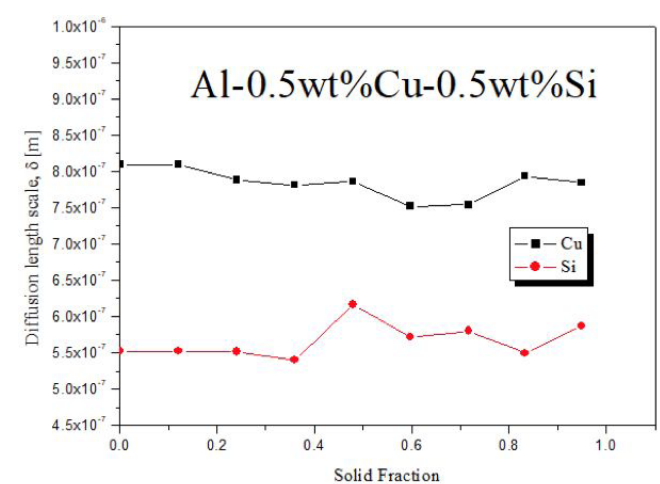

(A)

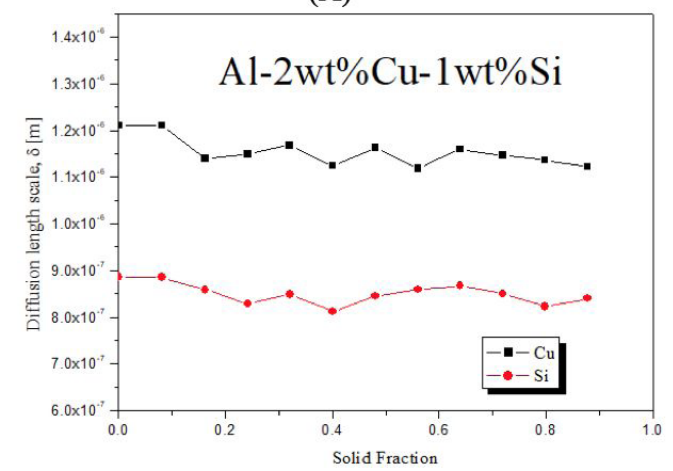

(C)

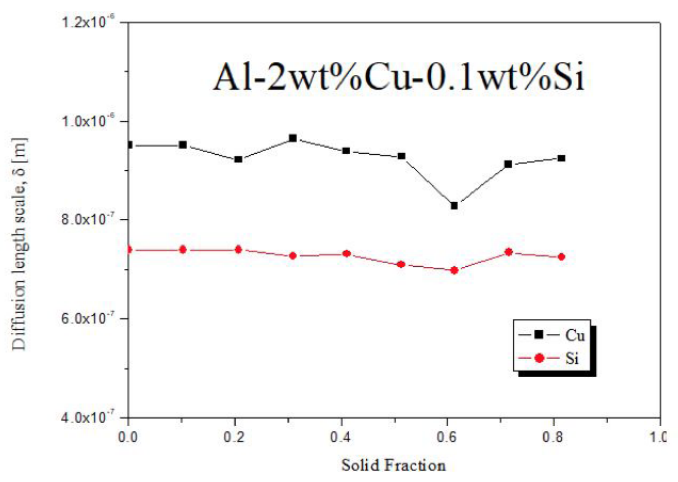

(B)

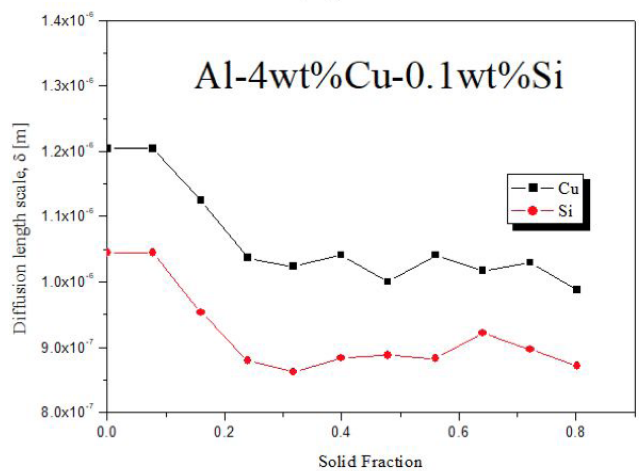

(D)

Figure 4. Diffusion length scale as a function of solid fraction for: (A) $\mathrm{Al}-0.5 \mathrm{wt} \% \mathrm{Cu}-0.5 \mathrm{wt} \% \mathrm{Si}$, (B) $\mathrm{Al}-2.0 \mathrm{wt} \% \mathrm{Cu}-0.1 \mathrm{wt} \% \mathrm{Si}$, (C) Al-2.0wt $\% \mathrm{Cu}-1.0 \mathrm{wt} \% \mathrm{Si}$, (D) $\mathrm{Al}-4.0 \mathrm{wt} \% \mathrm{Cu}-0.1 \mathrm{wt} \% \mathrm{Si}$ alloys.

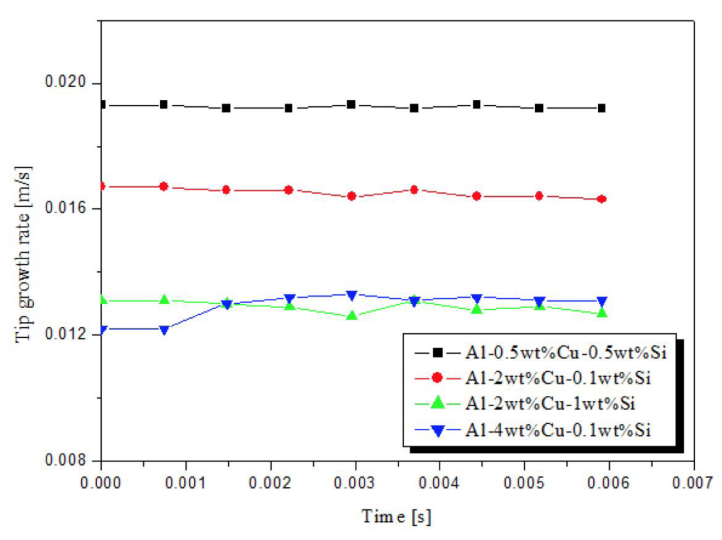

Figure 5. Tip growth rate as a function of time for: $\mathrm{Al}-0.5 \mathrm{wt} \% \mathrm{Cu}-$ $0.5 \mathrm{wt} \% \mathrm{Si}, \mathrm{Al}-2.0 \mathrm{wt} \% \mathrm{Cu}-0.1 \mathrm{wt} \% \mathrm{Si}, \mathrm{Al}-2.0 \mathrm{wt} \% \mathrm{Cu}-1.0 \mathrm{wt} \% \mathrm{Si}$ and $\mathrm{Al}-4.0 \mathrm{wt} \% \mathrm{Cu}-0.1 \mathrm{wt} \% \mathrm{Si}$ alloys.

alloy, for which a higher rate of coarsening of cellular spacing at the initial stage of solidification is observed, then, it decreases gradually until the solidification is complete. For the case of the $\mathrm{Al}-2 \mathrm{wt} \% \mathrm{Cu}-1.0 \mathrm{wt} \% \mathrm{Si}$ alloy, a higher rate of coarsening can be seen until it stabilizes horizontally in the range between $3 \mu \mathrm{m}$ and $7 \mu \mathrm{m}$, then, it increases its rate again up to $8 \mu \mathrm{m}$, from where $\lambda \mathrm{c}$ becomes constant. Comparing all the cases, the $\mathrm{Al}-4 \mathrm{wt} \% \mathrm{Cu}-0.1 \mathrm{wt} \% \mathrm{Si}$ alloy provides the highest rate of coarsening, with two shorts constant intervals between the lowest and the highest $\lambda \mathrm{c}$ values, until the half of

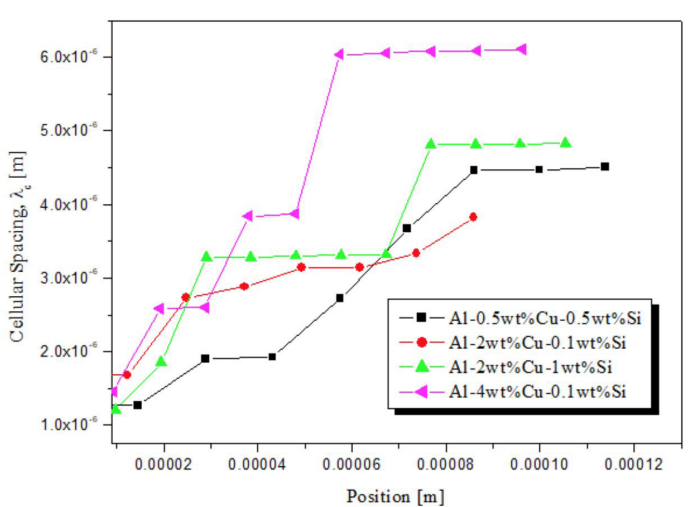

Figure 6. Cellular spacing $\left(\lambda_{\mathrm{C}}\right)$ as a function of position for: Al$0.5 \mathrm{wt} \% \mathrm{Cu}-0.5 \mathrm{wt} \% \mathrm{Si}, \mathrm{Al}-2.0 \mathrm{wt} \% \mathrm{Cu}-0.1 \mathrm{wt} \% \mathrm{Si}, \mathrm{Al}-2.0 \mathrm{wt} \% \mathrm{Cu}-$ $1.0 \mathrm{wt} \% \mathrm{Si}$ and $\mathrm{Al}-4.0 \mathrm{wt} \% \mathrm{Cu}-0.1 \mathrm{wt} \% \mathrm{Si}$ alloys.

the solidification domain is reached, from where a constant value remains until the end of the solidification process.

\section{Conclusions}

The paper presented a numerical analysis of the microstructural evolution during transient solidification of dilute Al-Cu-Si alloys, by the application of a phase field approach. The applied phase-field model was shown to be physically consistent with theoretical expressions for the 
solidification of alloys, regarding infinite back-diffusion (Lever Rule), no back-diffusion (Scheil Equation) and a finite back-diffusion in the solid phase (Clyne-Kurz form of the Brody Flemings model). The simulation results laid between the two limiting cases, i.e., the Lever Rule and the Scheil Equation. Concerning the calculated partition coefficient, for all cases, they were shown to be located between the equilibrium $\left(k_{0}\right)$ and the effective $\left(k_{\text {eff }}\right)$ partition coefficients. In the final stages of solidification, the simulated partition coefficients $\left(k_{e}\right)$ are equal or very close to $k_{\text {eff }}$. It was also demonstrated that, for all studied cases, $k_{\text {eff }}$ overestimate the solute redistribution between solid and liquid phases. The diffusion length scales for $\mathrm{Cu}$ and $\mathrm{Si}$ were calculated for all alloys, and it was shown that $\mathrm{Cu}$ provided the highest values for all analyzed cases. Concerning the diffusion length scales, a predominance of $\mathrm{Cu}$ values as compared to those of Si was observed to occur. Lower solute concentrations were shown to provide higher tip growth rates. For the two alloys of highest solute concentrations, a similar behavior was observed, except for the growth rate at the first instants of solidification. The $\mathrm{Al}-4 \mathrm{wt} \% \mathrm{Cu}-0.1 \mathrm{wt} \% \mathrm{Si}$ alloy presented the highest rate of coarsening of all alloys examined. The cellular spacing was shown to increase for all alloys as the solidification proceeds, until it stabilizes around certain value at the final stages of solidification.

\section{Acknowledgements}

The authors acknowledge the financial support provided by FAPERJ (The Scientific Research Foundation of the State of Rio de Janeiro -Brazil), CAPES (Coordenação de Aperfeiçoamento de Pessoal de Nível Superior - Brazil Finance Code 001) and CNPq (National Council for Scientific and Technological Development -Brazil).

\section{References}

1. Kobayashi R. Modeling and numerical simulations of dendritic crystal growth. Physica D. 1993;63:410-23.

2. Kim SG, Kim WT, Suzuki T. Phase-field model for binary alloys. Phys Rev E Stat Phys Plasmas Fluids Relat Interdiscip Topics. 1999;60:7186-97.

3. Furtado AF, Silva AJ, Castro JA. Simulation of the solidification of pure nickel via the phase-field method. Mater Res. 2006;9:349-56.

4. Lee SM, O'reilly KAQ, Cantor B, Hong CP. Microstructural transitions in $\mathrm{Al}-\mathrm{Cu}$ ribbons manufactured by planar flow casting. Mater Sci Eng A. 1998;249:233-40.

5. Kim SG, Kim WT, Suzuki T. Phase-field model for binary alloys. Phys Rev E. 1999;60:7186-97.

6. Ode M, Lee JS, Kim SG, Kim WT, Suzuki T. Phase-field model for solidification of ternary alloys. ISIJ Int. 2000;40:870-6.

7. Ferreira AF, Castro JA, Ferreira LO. Predicting secondarydendrite arm spacing of the $\mathrm{Al}-4.5 \mathrm{wt} \% \mathrm{Cu}$ alloy during unidirectional solidification. Mater Res. 2016;20. http://dx.doi. org/10.1590/1980-5373-mr-2015-0150.

8. Salvino IM, Jácome PAD, Ferreira AF, Ferreira IL. An analysis of the physical properties of multicomponent alloy on the simulation solidification by phase-field model. Materials Science Forum (Online). 2012;730(732):703-8.
9. Ferreira IL, Garcia A. The application of numerical and analytical approaches for the determination of thermophysical properties of Al-Si-Cu-Mg alloys. Contin Mech Thermodyn. 2020;32:123144. http://dx.doi.org/10.1007/s00161-019-00836-5.

10. Sales RC, Felipe P Jr, Paradela KG, Garção WJL, Ferreira AF. Effect of solidification processing parameters and silicon content on the dendritic spacing and hardness in hypoeutectic Al-Si alloys. Mater Res. 2018;21:1-8.

11. Paradela KG, Baptista LA. S., Sales RC, Felipe P Jr, Ferreira AF. Investigation of thermal parameters effects on the microstructure, microhardness and microsegregation of $\mathrm{Cu}$ Sn alloy directionally solidified under transient heat flow conditions. Mater Res. 2019;22. http://dx.doi.org/10.1590/19805373-MR-2019-0259.

12. Kim JT, Lee SW, Hong SW, Hong SH, Park HJ, Park JY, et al. Understanding the relationship between microstructure and mechanical properties of $\mathrm{Al}-\mathrm{Cu}-\mathrm{Si}$ ultrafine eutectic composites. Mater Des. 2016;92:1038-45.

13. Kim JT, Hong SH, Kim YS, Park HJ, Maity T, Chawake N, et al. Cooperative deformation behavior between the shear band and boundary sliding of an Al-based nanostructure-dendrite composite. Mater Sci Eng A. 2018;735:81-8.

14. Kim JT, Hong SH, Park JM, Kim KB. Microstructure and mechanical properties of hierarchical multi-phase composites based on Al-Ni-type intermetallic compounds in the Al-Ni-CuSi alloy system. J Alloys Compd. 2018;749:205-10.

15. Wheeler AA, Boettinger WJ, McFadden GB. Phase-field model for isothermal phase transitions in binary alloys. Phys Rev A. 1992;45:7424-39.

16. Zhao, J. Wang, Q. Yang, X. Numerical approximations for a phase field dendritic crystal growth model based on the invariant energy quadradization approach. Int J Numer Meth Eng. 2016;110(3):279-300. https://doi.org/10.1002/nme.5372.

17. Burton JA, Prim RC, Slichter WP. The distribution of solute in crystals grown from the Melt. Part I. Theoretical. J Chem Phys. 1953;21:1987-91.

18. Liu MX, Wang K, Xia D, Jiang T. Phase field simulation of Al-Si binary dendritic growth and micro-segregation patterns under convection. J Alloys Compd. 2014;589:431-5.

19. Nascimento FC, Paresque MCC, Castro JA, Jacome PAD, Garcia A, Ferreira IL. Application of computational thermodynamics to the determination of thermophysical properties as a function of temperature for multicomponent Al-based alloys. Thermochim Acta. 2015;619:1-7.

20. Ferreira DJS, Bezerra BN, Collyer MN, Garcia A, Ferreira IL. The use of computational thermodynamics for the determinations of surface tensions and Gibbs-Thomson coefficient of multicomponent alloys. Contin Mech Thermodyn. 2018;30:1145-54.

21. Scheil E. Bemerkungen zur Schichtkristallbildung Z. Metallk. 1942;34:70-2.

22. Flemings MC, Poirier DR, Barone RV, Brody HD. Microsegregation in iron-base alloys. J Iron Steel Inst. 1970;208:371-81.

23. Clyne TW, Kurz W. Solute redistribution during solidification with rapid solid state diffusion. Metall Trans, A, Phys Metall Mater Sci. 1981;12:965-71.

24. Voller VR. On a general back-diffusion parameter. J Korean Cryst Growth Cryst Technol. 2011;226:562-8.

25. Ferreira IL, Moreira ALS, Aviz JAS, Costa TA, Rocha OL, Barros AS, et al. On an expression for the growth of secondary dendrite arm spacing during non-equilibrium solidification of multicomponent alloys: validation against ternary aluminum-based alloys. J Manuf Process. 2018;35:634-50. 